\title{
Las cargas probatorias en la responsabilidad civil médica a partir de la doctrina y la jurisprudencia de la Corte Suprema de Justicia
}

\author{
Iván Santos-Ballesteros* \\ Emma Ortiz-Arciniegas ${ }^{* *}$ \\ Ruth Ruiz-Alarcón ${ }^{\star * *}$
}

\footnotetext{
Doctor en Derecho. Coordinador de la línea de derecho procesal en pregrado y de la Especialización en Derecho Procesal Civil. Profesor de pregrado y posgrado, Universidad Autónoma de Bucaramanga (UNAB), Bucaramanga, Colombia. Correo electrónico: isantos2@unab.edu.co.

** Especialista en Derecho Público y en Educación y Nuevas Tecnologías de la UNAB. Coordinadora académica de la modalidad virtual y profesora de pregrado y posgrado, Facultad de Ciencias Jurídicas y Políticas, Universidad Autónoma de Bucaramanga (UNAB), Bucaramanga, Colombia.

Correo electrónico: eortiz@unab.edu.co.

*** Diploma de Estudios Avanzados del programa de Doctorado en Derecho de la Universidad de Alcalá, España. Coordinadora de la línea de derecho laboral en pregrado y directora de la Especialización en Responsabilidad Médica. Docente de pregrado y posgrado, Universidad Autónoma de Bucaramanga (UNAB), Bucaramanga, Colombia. Correo electrónico: rruiz2@unab.edu.co.
}

Recibido: 16 de diciembre del 2015 Aprobado: 13 de enero del 2016

Cómo citar este artículo: Iván SantosBallesteros, Emma Ortiz-Arciniegas, Ruth Ruiz-Alarcón. Las cargas probatorias en la responsabilidad civil médica a partir de la doctrina y la jurisprudencia de la Corte Suprema de Justicia. DIxI 23. Abril 2016. Pág. 57. doi: http://dx.doi.org/10.16925/ di.v18i23.1291

\section{Resumen}

Introducción: el presente artículo constituye un resultado del proyecto de investigación del mismo nombre, el cual se desarrolla en el grupo de investigación Hermenéutica Jurídica de la línea de investigación Análisis Jurídico, de la Facultad de Derecho de la Universidad Autónoma de Bucaramanga (UnAB). Metodología: tiene como objetivo analizar la evolución doctrinal y jurisprudencial de la Sala Civil de la Corte Suprema de Justicia sobre la carga de la prueba en los procesos de responsabilidad médica, en el periodo comprendido entre 1990 y el 2014, con referencia a esta última. Es necesario señalar que, sobre la demostración del supuesto de hecho de las normas que consagran el efecto jurídico que ellas persiguen en procesos de responsabilidad médica, surge el interrogante en torno a si la carga probatoria le corresponde a la parte demandante (carga probatoria estática) o bien, a la parte que está en mejores condiciones para aportar las evidencias o esclarecer los hechos de controversia, ya sea demandante o demandado (carga probatoria dinámica). Resultados y conclusiones: la respuesta la da la evolución en dos de los pronunciamientos de la Corte Suprema de Justicia, denominadas para su análisis como fundadora de línea (Sentencia del 5 de marzo de 1940) y arquimédica (Sentencia del 14 de noviembre de 2014).

Palabras clave: carga dinámica de la prueba, carga estática, cargas procesales, doctrina, consagración legal, sentencias de la Corte Suprema de Justicia. 


\title{
Burdens of Proof in Medical Civil Liability Based on Doctrine and Case Law of the Supreme Court of Justice
}

\begin{abstract}
Introduction: this article is the result of a research project with the same name conducted by the research group Legal Hermeneutics of the research line Legal Analysis in the School of Legal and Political Sciences at the Universidad Autónoma de Bucaramanga (UNAB), Colombia. Methodology: the research conducted is descriptive with documentary review techniques; the deductive method is used. Its general objective is to analyze the doctrine and case law evolution of the Civil Division of the Supreme Court of Justice in terms of burden of proof in medical liability proceedings for the period between 1990 and 2014. It is noteworthy that, regarding the demonstration of the de facto assumption of the rules containing the legal effect they pursue in medical liability proceedings, there is a question about whether the burden of proof belongs to the plaintiff (static burden of proof) or to the party who is in the best condition to bring in evidence or clarify the facts of the dispute, whether plaintiff or defendant (dynamic burden of proof). Results and conclusions: the answer to the said legal problem is given by the evolution of two pronouncements by the Supreme Court of Justice, referred to for their analysis as line founder (Judgment of March 5, 1940) and Archimedean (Judgement of November 14, 2014).
\end{abstract}

Keywords: dynamic burden of proof, static burden, procedural burden, doctrine, legal establishment, judgments of the Supreme Court of Justice.

\section{As cargas probatórias na responsabilidade civil médica a partir da doutrina e da jurisprudência da Suprema Corte de Justiça}

\section{Resumo}

Introdução: o presente artigo constitui um resultado do projeto de pesquisa do mesmo nome, o qual se desenvolve no grupo de pesquisa Hermenêutica Jurídica da linha de pesquisa Análise Jurídica, da Faculdade de Ciências Jurídicas e Políticas da Universidad Autónoma de Bucaramanga (UnAB), Colômbia. Metodologia: a pesquisa realizada é de tipo descritivo, com técnicas de revisão de documentos; emprega-se o método dedutivo. Tem como objetivo geral analisar a evolução doutrinal e jurisprudência da Sala Civil da Suprema Corte de Justiça sobre a carga da prova nos processos de responsabilidade médica, no período compreendido entre 1990 e 2014. É necessário apontar que, sobre a demonstração da hipótese formulada das normas que consagram o efeito jurídico que elas perseguem em processos de responsabilidade médica, surge o interrogante em torno de se a carga probatória corresponde à parte demandante (carga probatória estática), ou bem, à parte que se encontra em melhores condições para contribuir com evidências ou esclarecer os fatos de controvérsias, seja demandante, seja demandado (carga probatória dinâmica). Resultados e conclusões: a resposta ao anterior problema jurídico vem dada pela evolução de dois dos pronunciamentos da Suprema Corte de Justiça, denominados para sua análise, como fundadora de linha (Sentença de 5 de março de 1940) e arquimédica (Sentença de 14 de novembro de 2014).

Palavras-chave: carga dinâmica da prova, carga estática, cargas processuais, doutrina, consagração legal, sentenças da Suprema Corte de Justiça. 


\section{INTRODUCCIÓN}

Este estudio es un análisis histórico, jurisprudencial y doctrinal de la carga de la prueba en procesos de responsabilidad civil médica, teniendo en cuenta que antes de la Ley 1564 de 2012, la cual consagra la carga dinámica de la prueba, la Constitución Política, el Código Civil y el Código de Procedimiento Civil ya establecían la carga de la prueba. La importancia de este artículo radica en que es una recopilación histórica desde la concepción de Leo Rosemberg y Jeremías Bentham, y en los tiempos modernos se incluye la doctrina argentina que revivió la teoría de la carga dinámica. Este pensamiento fue acogido por los países latinoamericanos, y Colombia no es ajena a esta situación, como se establece en la jurisprudencia de la Corte Suprema de Justicia el 30 de enero de 2001, siendo magistrado ponente José Fernando Ramírez Gómez.

La carga de la prueba, en sus dos concepciones de estática y dinámica, ha sido objeto de estudio desde las diferentes épocas del Derecho procesal; por consiguiente, no es producto del moderno Derecho probatorio.

Así, dos de los autores más reconocidos en el campo del Derecho probatorio plantearon las anteriores posiciones al respecto. Según Leo Rosemberg, ${ }^{1}$ no ejerce influencia sobre la carga de la prueba ni el principio de la "buena fe entre las partes, ni la dificultad o la imposibilidad del suministro de la prueba". ${ }^{2}$ Y señala posteriormente que "en ningún caso la dificultad e inclusive la imposibilidad de suministrar la prueba puede llevar a una modificación de nuestro principio respecto de la carga de la prueba". ${ }^{3}$

Por su lado, Bentham, ${ }^{4}$ ante el interrogante sobre la parte que debe asumir la obligación probatoria, respondió:

Esta cuestión presenta en el sistema del procedimiento técnico infinitas dificultades. En el sistema de justicia franca y sencilla del procedimiento natural nada hay más fácil que responder a esta pregunta. La obligación de la prueba debe en cada caso individual imponerse a aquella parte que pueda practicarla con

1. Véase Leo Rosemberg. La CARga de la PRUeba. Editorial B de F. (2002). Pág. 183.

2 Id.

3 Id. Pág. 378.

4. Véase Jeremías Bentham. Tratado de LAS PRUEbas Judiciales. Ediciones Nueva Jurídica. (2000). Pág. 98. menos inconvenientes, es decir, con menos dilaciones, vejámenes y gastos. ${ }^{5}$

5. A manera de breve historia de la carga de la prueba $-\mathrm{y}$ de su distribución-, Devis Echandía señala cómo en el antiguo derecho romano (en el procedimiento de la legis actio sacramento, y en general en el proceso per actions) la carga de la prueba le correspondía a ambas partes. En el período clásico se dictaron normas que imponían indistintamente la carga de la prueba, según la controversia, con un criterio basado en la equidad. Posteriormente, en el derecho justinianeo "surgieron principios generales, y en particular, el fundamental que ponía a cargo de quien afirmaba la existencia o inexistencia de un hecho como base de su acción o excepción, la prueba de él, ya fuera actor o demandado". Véase Hernando Devis Echandía. Compendio de Derecho Procesal. Pruebas judiciaLES. Editorial Diké. (1994). Pág. 148 y ss. A partir de la dos últimas décadas del siglo pasado, esta teoría de las cargas dinámicas, o de flexibilidad de la cargas probatorias, resurge con entusiasmo merced a los escritos publicados en 1984 por los autores argentinos Jorge Peyrano y Julio O. Chiappini, en los que señalaron, de acuerdo con las circunstancias de cada caso, cómo las cargas probatorias pueden desplazarse hacia cualquiera de las partes, y de esta manera se llegue a servir mejor a la justicia respecto al asunto que se presenta a los estrados judiciales y que, como se sabe, constituye la meta del proceso civil contemporáneo. Véase Jorge Peyrano y Julio O. Chiappini. Lineamientos generales de las cargas probatorias "dinámicas". CARGAS PROBATORIAS DINÁMICAs. Rubinzal-Culzoni Editores. (2004). Pág. 19. Esta teoría muy pronto se difundió en su mismo país y en otros latinoamericanos, entre ellos Colombia, para la solución de controversias relacionadas con la responsabilidad médica tradicional y la responsabilidad estatal. Así, en 1992, en sentencia de la Sección Tercera, Sala de lo Contencioso Administrativo del Consejo de Estado, se expresó: "Ahora bien, por norma general le corresponde al actor la demostración de los hechos y cargos relacionados en la demanda. Sin embargo, con mucha frecuencia se presentan situaciones que le hacen excesivamente difícil, cuando no imposible, las comprobaciones respectivas, tal el caso de las intervenciones médicas, especialmente quirúrgicas, que por su propia naturaleza, por su exclusividad, por la privacidad de las mismas, por encontrarse en juego intereses personales o institucionales, etc., en un momento dado se constituyen en barreras infranqueables, para el paciente, para el ciudadano común obligado procesalmente a probar aspectos científicos o técnicas profesionales sobre los cuales se edifican los cargos que por imprudencia, negligencia o impericia formula en el ejercicio de una determinada acción judicial, contra una institución encargada de brindar servicios médicos u hospitalarios (...) Sin duda, resultaría más beneficioso para la administración de justicia en general, resolver esta clase de conflictos, si en lugar de someter al paciente, normalmente el actor o sus familiares, a la demostración de las fallas en los servicios y técnicas científicas prestadas por especialistas, fueran éstos los que por encontrarse en las mejores condiciones de conocimiento técnico y real por cuanto ejecutaron la respectiva conducta profesional, quienes satisficieran directamente las inquietudes y cuestionamientos que contra sus procedimientos se formulan (...) Podrán así los médicos exonerarse de responsabilidad y con ello los centros clínicos oficiales que sirven al paciente, mediante la comprobación, que para ellos, se repite, es más fácil y práctica, de haber actuado con la eficiencia, prudencia o idoneidad requeridas por las circunstancias propias al caso concreto, permitiéndose al juzgador un mejor conocimiento de las causas, procedimientos, técnicas y motivos que llevaron al profesional a asumir determinada conducta 
Uno de los principios constitucionales del Derecho procesal relacionado con la institución de la carga de la prueba es el de la igualdad de las partes. No existirá verdadera igualdad procesal en el evento en que surjan entre las partes diferencias económicas y sociales, o en aquellos casos en que se le exija al actor la prueba de un hecho de muy difícil acreditación.

La verdadera igualdad dentro del universo procesal, y relacionada con la carga de la prueba, es la que tiene en cuenta, en ciertos casos, a quién se le facilita la demostración de un hecho concreto. El adjudicarle a la parte a quien se le facilita la demostración del hecho no es más que la invocación de la carga dinámica de la prueba. ${ }^{6}$

Los aspectos anteriores están contenidos en esta muestra del trabajo investigativo; se inicia con una aproximación genérica al estudio de la carga procesal: su noción y utilidad; la evolución jurisprudencial en torno a la carga de la prueba; la carga dinámica de la prueba y su actual consagración legal en el Código General del Proceso (c.G. del P.); su concepción en la doctrina colombiana y extranjera; $y$, por último, se finaliza con el análisis de la evolución que esta teoría ha tenido en la jurisprudencia de la Corte Suprema de Justicia, Sala Civil y Agraria, y las conclusiones pertinentes.

\section{CARGAS PROCESALES}

Los imperativos jurídicos, denominados así en la doctrina procesal, se distinguen en la relación jurídica procesal como deberes, obligaciones y cargas procesales. Los deberes procesales son aquellos consagrados en la ley, encaminados a la adecuada realización del proceso. Miran, según el sujeto llamado a observarlos, al juez (artículo 42 c.G. del P., Ley 1564 de 2012), a las partes y a sus apoderados (artículo 78, Ley 1564 de 2012). Estos deberes emanan de la ley

o tratamiento". Véase Consejo de Estado. Sección Tercera, Sala de lo Contencioso Administrativo. SENTENCIA DEL 30 DE JULIO DE 1992. (M.P. Daniel Suárez Hernández; Julio 30 de 1992). En el mismo sentido, se pronunció la Corte Suprema de Justicia en su Sala Civil y Agraria, calificada como una de las sentencias hitos en este trabajo investigativo: "En el Derecho patrio, como en otras legislaciones, la norma reguladora de la carga de la prueba (artículo 177 del Código de Procedimiento Civil) no se opone a la flexibilidad de la misma, en atención a las circunstancias especiales de cada caso, en particular, ni en forma expresa o tácita". Véase Corte Suprema de Justicia. Sala Civil y Agraria. Expediente N. ${ }^{\circ}$ 5507. (M.P. José Fernando Ramírez; Enero 30 de 2001).

6. Véase Jairo Parra Quijano. Manual de Derecho Probatorio. Librería Ediciones del Profesional. (2004) Pág. 236. procesal, pertenecen al campo del Derecho público y, por consiguiente, son de obligatorio cumplimiento, según lo consagra el artículo 13 del mismo estatuto procesal:

Las cargas procesales son aquellas situaciones instituidas por la ley que comportan o demandan una conducta de realización facultativa, normalmente establecida en interés del propio sujeto y cuya omisión trae aparejadas para él consecuencias desfavorables, como la preclusión de una oportunidad o un derecho procesal e inclusive hasta la pérdida del derecho sustancial debatido en el proceso (...) Como se ve, las cargas procesales se caracterizan porque el sujeto a quien se las impone la ley conserva la facultad de cumplirlas o no, sin que el Juez o persona alguna pueda compelerlo coercitivamente a ello, todo lo contrario con lo que sucede con las obligaciones; empero, si quiere obtener determinado resultado tendrá que cumplirlas; de no, tal omisión le puede acarrear consecuencias desfavorables. Así, por ejemplo probar los supuestos de hecho para no recibir una sentencia adversa a sus pretensiones.?

Devis Echandía, ${ }^{8}$ en referencia a la carga procesal, señala:

Es un poder o una facultad (en sentido amplio), de ejecutar libremente ciertos actos o adoptar cierta conducta prevista en la norma para beneficio y en interés propio, sin sujeción ni coacción y sin que exista otro sujeto que tenga el derecho a exigir su observancia, pero cuya inobservancia acarrea consecuencias desfavorables.

\section{NOCIÓN Y UTILIDAD}

\section{DE LA CARGA DE LA PRUEBA}

A fin de llegar al conocimiento de esta figura de la carga de la prueba, es preciso distinguir dos de sus aspectos. Por el primero de ellos, se considera como regla para el juez o regla de juicio, al permitirle que decida de fondo la controversia, y no que se abstenga de hacerlo, en el evento de que no exista prueba suficiente (non liquet) para el reconocimiento del derecho del demandante.

\footnotetext{
7. Véase Corte Suprema de Justicia. Sala de Casación Civil. Auto DE FECHA 17 DE SEPTIEMBRE DE 1985.

8. Véase Hernando Devis Echandía, supra, nota 5. Pág. 148.
} 
Por el segundo aspecto, se constituye en una regla de conducta para las partes, al señalarles indirectamente cuáles deben ser los hechos que a cada una ellas les interesa probar. Las anteriores consideraciones son tenidas en cuenta por Devis Echandía para definir esta institución:

Carga de la prueba es una noción procesal, que contiene la regla de juicio por medio de la cual se le indica al juez cómo debe fallar, cuando no encuentra en el proceso pruebas que le den certeza sobre los hechos que deben fundamentar su decisión, e indirectamente establecer a cuál de las partes le interesa la prueba de tales hechos, para evitar las consecuencias desfavorables a ella o favorable a la otra parte. ${ }^{9}$

La carga de la prueba, por regla general, implica para el demandante probar los hechos que fundamentan su pretensión, al igual que la parte demandada debe demostrar los hechos de su defensa. Si no aparece acreditado un hecho dentro del proceso, el juez en su decisión final deberá determinar a cuál de ellas aquella no le favorece.

Al respecto, Ricardo Luis Lorenzetti señala ${ }^{10}$ que el concepto de carga ha sido estudiado en diversas disciplinas, pero que es en el campo del Derecho procesal donde se han definido los perfiles conceptuales más nítidos.

Un grupo de nociones - agrega el autor- estaría formado por aquellas que miran el aspecto pasivo de la idea. Para un parte de la doctrina viene a ser una categoría dentro de las obligaciones, respecto a la cual no existe sanción alguna en estricto sentido, sino decadencia. Esta sería una pérdida de orden económico que genera un fenómeno de "autorresponsabilidad".

Otros autores han acentuado el carácter público de la carga de la prueba, el cual surgiría de las numerosas imposiciones de esta naturaleza que suelen existir en las Constituciones (en relación con el proceso habría un interés en una buena administración). Esta noción descuida la idea de libertad básica en el sujeto para cumplir o no con la carga, debilidad que ha motivado cierto desdén de la doctrina mayoritaria.

Otro grupo de juristas insiste en la libertad probatoria, pero señala como conveniente observar determinado comportamiento si las partes aspiran a evitar consecuencias desfavorables sin que constituya sanción alguna.

9. Id. Págs. 150 y ss.

10. Véase Ricardo Luis Lorenzetti. ResPonsabiLIDAD CIVIL DE LOS MÉDicos. Tomo II. Rubinzal-Culzoni Editores. (1997). Págs. 202 y
Finalmente, hay coincidencia en otros autores al hacer énfasis en el interés particular. Así, Carnelutti distingue entre el acto necesario (el que debe ejecutarse si se busca obtener una finalidad en interés propio) y el acto debido (que es el acto jurídico clásico). En el primer caso, se presentaría una sanción económica. Los debates se han originado entre si este interés es jurídico - con lo cual se asimilaría a la carga de la obligación- o si por el contrario se trata de un fenómeno extrajurídico o mera coacción psicológica como lo ha sostenido Michelli, seguido en ello por la doctrina mayoritaria.

Se ha venido perfilando la concepción actual, elaborada por Rosemberg en la doctrina alemana, por Michelli en la italiana y por Devis Echandía en la latinoamericana, la cual apunta a concebir la carga de la prueba como facultad de obrar en beneficio propio, sin ninguna coacción ni ilicitud, como una conveniencia práctica y no como deber jurídico; como imperativo del propio interés.

Termina Ricardo Luis Lorenzetti señalando que la carga de la prueba:

Es entonces la facultad que se adjudica a las partes de probar, en su propio interés, los hechos que fundamentan su pretensión. No se puede obligar a alguien a probar, pero si no lo hace, el hecho no será considerado por el sentenciante. ${ }^{11}$

La regla sobre la carga de la prueba, según Liebman, ${ }^{12}$ adquiere su mayor relieve en el momento en que el juez entra a decidir, porque es en esta oportunidad cuando obtiene las consecuencias de la falta de la prueba, pronunciándose en sentido desfavorable a la parte que ha debido aportarla. De ahí que la regla sobre la carga de la prueba se resuelva en el momento de la decisión, en una "regla de juicio" que representa la natural consecuencia y, por consiguiente, la "sanción" de la falta de cumplimiento por la parte que estaba obligada a ello. Los dos aspectos de la regla, vale decir, la carga para la parte y la de juicio para el juzgador, no pueden, sin embargo, disociarse y contraponerse, porque son estricta y lógicamente conexos entre sí, y son los dos lados y los dos momentos inseparables de una regla de carácter unitario.

En este contexto, Ramos Méndez señala que el juez al momento de la evaluación probatoria y antes de decidir, puede encontrarse con hechos necesarios de prueba que sin embargo no se han acreditado,

\footnotetext{
11. Id.

12. Véase Enrico Tullio Liebman. Manual de Derecho Procesal Civil. Ediciones Jurídicas Europa América. (1980). Pág. 294.
} 
y se ve obligado a fallar el pleito, pues así se lo impone la ley (artículos 361 Ley de Enjuiciamiento Civil (LEC) y 1, 7 CC). No puede aducir la falta de pruebas para omitir pronunciarse. En tales casos, se le ofrece un mecanismo sustitutivo que opera mediante el siguiente razonamiento: ¿qué hecho debiera ser probado y quién debería probarlo? A esa parte le ha de perjudicar la decisión; el juez actúa en consonancia, y le atribuye todas las consecuencias de la falta de prueba al litigante que está gravado con la carga probatoria. Es entonces cuando el mecanismo de la carga de la prueba constituye el correctivo a la posibilidad de non liquet. ${ }^{13}$

\section{LA CARGA DE LA PRUEBA EN LA JURISPRUDENCIA COLOMBIANA}

\section{A. Corte Suprema de Justicia}

Recuérdese que toda "decisión judicial debe fundarse en las pruebas regular y oportunamente allegadas al proceso", sujetas a su valoración racional e integral, "de acuerdo con las reglas de la sana crítica, sin perjuicio de las solemnidades prescritas en la ley sustancial para la existencia o validez de ciertos actos" - artículos 174 y 187, Decreto 1400 de 1970 del Código de Procedimiento Civil (c. de P.C.) - , con lo que corresponde al demandante y no al juez la carga probatoria (actori incumbit probatio), con elementos probatorios idóneos y sujetos a contradicción, y en contrapartida, al demandado corresponde demostrar in contrario (reus in excipiendo fit acto). Esto debido a que, al tenor del artículo 177, Decreto 1400 de 1970 del C. de P.C., "incumbe a las partes probar el supuesto de hecho de las normas que consagran el efecto jurídico que ellas persiguen", cuestión que en la autorizada opinión de Francisco Carnelutti:

Se desarrolla en procura de demostrar los supuestos fácticos que sustentan su proposición. También la noción de carga de la prueba incluye para el juzgador una regla de juicio que le indica cómo debe fallar cuando no encuentra la demostración de los hechos en que se fundamenta la pretensión o la excepción (...) y se traduce en la obligación del juez de considerar existente o inexistente un hecho según que una

13. Véase Francisco Ramos Méndez. Derecho Procesal Civil. Librería Bosch Barcelona. (1986). Págs. 555 y ss. de las partes le ofrezca o no la demostración de su inexistencia o de su existencia. ${ }^{14}$

De otra parte, la Corte Suprema plantea:

Por lo mismo, siendo del actor y no del juez el deber de demostrar los supuestos fácticos de las normas jurídicas, cuando se omite pronunciamiento sobre una prueba solicitada, es la parte afectada la legitimada para interponer recurso de reposición en dicha instancia, en los términos del artículo 348 del c.P.C. o en alzada, en virtud de lo establecido en el numeral tercero del artículo 351 ídem. En conclusión, la carencia de diligencia de la parte en cuestiones probatorias, no conduce a que el juzgador se vea obligado inexorablemente a actuar por ella mediante el decreto oficioso de pruebas. ${ }^{15}$

La Corte Suprema de Justicia ${ }^{16}$ también se ha referido al artículo 167 del Código General del Proceso (c.G.P):

Igualmente, es menester recordar al respecto que ya esta corporación, en el mencionado fallo del 30 de enero de 2001, destacó que (...) Todo, se reitera, teniendo en cuenta las características particulares del caso: autor, profesionalidad, estado de la técnica, complejidad de la intervención, medios disponibles, estado del paciente y otras circunstancias exógenas, como el tiempo y el lugar del ejercicio, pues no de otra manera, con justicia y equidad, se pudiera determinar la corrección del acto médico (lex artis) (...) Esta última referencia es particularmente importante en situaciones excepcionales, en las que exista una evidente dificultad probatoria para el paciente o sus familiares en orden a obtener los medios de prueba que sirvan para acreditar la culpa médica; y por el contrario, por cercanía o disponibilidad, la demostración de la diligencia resulte de mayor facilidad para el facultativo o la institución hospitalaria demandada. En tales supuestos, obviamente, debe existir suficiente claridad en cuanto a la distribución probatoria que se determine para el caso particular, adoptada

14. Véase Francisco Carnelutti. La prueba Civil. Niceto AlcaláZamora y Castillo, Trad. Ediciones Depalma. (1979). Págs. 219 y ss. 15. Véase Corte Suprema de Justicia. Sala de Casación Civil y Agraria. ExPEDIENTE 2002-00373-01. (M.P. William Namén; Enero 25 de 2008).

16. Véase Corte Suprema de Justicia. Sala de Casación Civil. Expediente 2005-00025-01. (M.P. Arturo Solarte; Noviembre 5 de 2013). Disponible en https://docs.google.com/document/d/ 1lNY5LiH-pPn_O5qlGX8gWeqjtRnBYyrQQ2PufJEenGM/edit 
en el momento procesal oportuno y garantizando la adecuada defensa y contradicción de las partes. $\mathrm{Al}$ respecto, resulta pertinente tener presente, como criterio interpretativo mientras entra en vigor, que el inciso 2 del artículo 167 de la Ley 1564 de 2012 que adoptó el Código General del Proceso, luego de señalar que "incumbe a las partes probar el supuesto de hecho de las normas que consagran el efecto jurídico que ellas persiguen", introduce explícitamente el concepto de carga dinámica de la prueba en los siguientes términos: "No obstante, según las particularidades del caso, el juez podrá, de oficio o a petición de parte, distribuir la carga al decretar las pruebas, durante su práctica o en cualquier momento del proceso antes de fallar, exigiendo probar determinado hecho a la parte que se encuentre en una situación más favorable para aportar las evidencias o esclarecer los hechos controvertidos. La parte se considerará en mejor posición para probar en virtud de su cercanía con el material probatorio, por tener en su poder el objeto de prueba, por circunstancias técnicas especiales, por haber intervenido directamente en los hechos que dieron lugar al litigio, o por estado de indefensión o de incapacidad en la cual se encuentre la contraparte, entre otras circunstancias similares. (...) Cuando el juez adopte esta decisión, que será susceptible de recurso, otorgará a la parte correspondiente el término necesario para aportar o solicitar la respectiva prueba, la cual se someterá a las reglas de contradicción previstas en este código".

\section{CARgA DiNÁMiCA DE LA PRUEBA. Noción, CARACTERÍsTiCAS Y REQUISITOS}

Se hace referencia en forma concreta a la teoría de la carga dinámica de la prueba.

\section{A. Noción}

En el desarrollo de las Quintas Jornadas Bonaerenses de Derecho Civil, Comercial, Procesal e Informático, celebradas en Junín (la ciudad más importante del noroeste de la provincia de Buenos Aires, Argentina), en octubre de 1992, la Comisión de Derecho Procesal presentó la siguiente declaración:

La llamada doctrina de las cargas probatorias dinámicas puede y debe ser utilizada por los estrados ju- diciales en determinadas situaciones en las cuales no funcionan adecuada y valiosamente las previsiones legales que, como norma, reparten los esfuerzos probatorios. La misma importa un desplazamiento del onus probandi, según fueren las circunstancias del caso, en cuyo mérito aquel puede recaer, verbigracia, en cabeza de quienes están en mejores condiciones técnicas, profesionales o fácticas para producirlas, más allá del emplazamiento como actor o demandado o de tratarse de hechos constitutivos, impeditivos, modificativos o extintivos. ${ }^{17}$

La propuesta de la carga dinámica de la prueba se encamina a fortalecer la regla de juicio, de tal manera que el juez decida a cuál de las partes compele la carga de la prueba una vez haya valorado el resultado de su actividad de investigación, la conducta procesal de las partes, al igual que la disponibilidad o facilidad de cada uno respecto a la producción de los medios probatorios.

Desde este punto de vista, Trujillo Cabrera entiende por carga dinámica de la prueba, "aquella que incumbe a las partes de probar los hechos que le resulten de más fácil demostración, en comparación con la extrema dificultad de su adversario en demostrarlos, conforme a la experiencia de cada proceso."18

\section{B. Características}

\section{Es de aplicación excepcional}

Frente a la concepción clásica de la institución de la carga de la prueba, la teoría de la carga dinámica hace recaer el onus probandi sobre aquella de las partes que se encuentra en mejores condiciones profesionales, técnicas, económicas y fácticas para acreditar un hecho, de manera que cobra vigencia en situaciones de excepción, y en consecuencia, no se presenta de ordinario un desplazamiento absoluto o total de la distribución de la carga probatoria que se impone a los litigantes de acuerdo con las reglas tradicionales.

\section{El desplazamiento de la carga de la prueba es tan solo parcial, no total}

El desplazamiento del onus probandi que conlleva la aplicación de esta teoría se lleva a cabo, de ordinario,

17. Véase Jorge Peyrano y Julio O. Chiappini, supra, nota 4. Pág. 17. 18. Véase Juan Trujillo Cabrera. LA CARGA DE LA PRUEBA. Leyer Editorial. (2006). Pág. 50. 
solo respecto a algunos hechos y circunstancias, mas no a todo el material fáctico. Por consiguiente, tal característica no acarrea el desplazamiento total sino parcial; de ahí que se conserva en cabeza de la otra parte la imposición de determinados esfuerzos probatorios.

3. La parte que está en mejores condiciones de la prueba suele estar igualmente en mejor posición para desvirtuar la prueba en su favor

La parte que está en condiciones favorables para la producción probatoria, correlativamente, puede desvirtuarla en su provecho y sin ninguna dificultad. ${ }^{19}$

\section{Requisitos para su aplicación}

1. Dificultad o imposibilidad de una de las partes para acreditar los hechos que fundamentan su pretensión o su defensa

El supuesto de la dificultad probatoria implica que la parte sobre la que inicialmente recae la carga de la prueba tiene algún obstáculo para su producción, por no tener acceso al medio de prueba o por no poder aportar lo que le permita invocar el presupuesto de hecho planteado.

2. Mejor posición probatoria de la parte contraria en relación con el mismo presupuesto fáctico

Este segundo supuesto implica el que una de las partes tenga una mayor cercanía a la fuente de prueba requerida para acreditar los hechos invocados por la contraparte, de manera que aquella se encuentre en mejores condiciones para aportarla al proceso con menos obstáculos. Se considera que una de las partes se encuentra en tal situación para aportar una determinada prueba cuando atiende a la posibilidad exclusiva de su demostración, o por sus conocimientos profesionales o técnicos para acreditar un hecho de manera fehaciente, o aún por implicarle un menor costo económico. ${ }^{20}$

19. Véase Luis Guillermo Serrano Escobar. El RÉgIMEN PROBATORIO EN LA RESPONSABILIDAD MÉDICA. Ediciones Doctrina y Ley. (2012). Págs. 29 y ss. 20. Id. Págs. 30 y ss.

\section{LA CARGA DINÁMICA DE LA PRUEBA EN EL SISTEMA JURÍDICO COLOMBIANO}

El artículo 167 del Código General del Proceso la consagró. Su primer inciso es la reproducción de la distribución de la carga probatoria, tal como la concibe el Código de Procedimiento Civil, y que sigue los lineamientos de la teoría normativa de Rosemberg y Michelli, al señalar que, en principio, las partes han de probar los hechos que les sirven de fundamento a las reglas de contradicción que el mismo código prevé.

Los incisos segundo y tercero acogen el dinamismo probatorio cuando disponen que, a petición de parte o de oficio, el juez puede llegar a su distribución, teniendo en cuenta la posición más favorable de las partes para su aportación; y aquella que se considere en mejor posición de probar, en virtud de la cercanía al material probatorio, o bien por tener en su poder el objeto de prueba, atender a circunstancias técnicas especiales, por la intervención directa en los hechos que le dieron origen al litigio, o bien por el estado de indefensión o incapacidad en el cual se encuentra la contraparte, entre otras circunstancias similares.

Una inquietud que surge después de la consagración legislativa de la carga dinámica de la prueba tiene que ver con el momento procesal en el que el juez procede a su distribución. La norma contempla las siguientes posibilidades: al decretar las pruebas, durante la etapa de instrucción o en cualquier momento antes de proferir sentencia, con la exigencia a alguna de las partes de acreditar determinado hecho por considerar que se encuentra en situación más favorable para el aporte de las evidencias o el esclarecimiento de los hechos controvertidos.

Con la anterior solución sobre el momento procesal referido, se superan las inquietudes planteadas a nivel doctrinal, al echarlo de menos con el argumento de la sorpresa, ya que ahora la distribución probatoria podrá hacerla en cualquier etapa del proceso antes de fallar.

La consagración legislativa de la carga dinámica de la prueba en el Código General del Proceso constituye un acierto y se convierte en pionera en la región, otorgándole al juez la posibilidad de distribuirla, y considerándola como excepción al principio rígido del onus probandi, en el sentido de que era al demandante a quien le correspondía demostrar los hechos invocados en la demanda por tener la carga de la prueba, y no como se plantea en la norma, en el sentido de que el juez podrá asignar cargas probatorias a ambas 
partes, de tal manera que si la parte obligada a ello no aporta dichas pruebas, asumirá las circunstancias adversas ante el incumplimiento de este deber. ${ }^{21}$

Una vez consagrada en el Código General del Proceso la figura de la carga dinámica de la prueba, en su artículo 167 surgieron algunas inquietudes acerca de la dificultad en su aplicación.

Así, el profesor Acero Gallego ${ }^{22}$ considera que en el sistema de la carga dinámica la prueba constituye un cambio fundamental frente al modelo probatorio consagrado en el ordenamiento procesal colombiano desde hace varios años. No obstante lo anterior, agrega que el empleo de la carga dinámica de la prueba hará más compleja la actividad del juez. Lo anterior - señala- ocurrirá no solo por la mixtura que estableció el artículo 167 del Código General del Proceso entre los dos sistemas, sino por las consecuencias de un déficit probatorio una vez el juez ordene que ciertos supuestos de hecho sean demostrados por una de las partes .

El proyecto de Ley del Código General del Proceso, en referencia al tema de la carga dinámica de la prueba, expresó lo siguiente:

El derecho fundamental a la prueba implica que a ella se debe acceder sin obligar al necesitado a realizar actos de proeza o que sencillamente a pesar de tener ese derecho, le resulte imposible conseguirla, porque quien la puede desahogar es su contraparte y ésta no tiene interés en hacerlo. Frente a esta realidad y con sustento en el artículo 1 de la Constitución Política, se consagra que cuando a una de las partes le resulte más fácil probar determinados hechos, corresponde a ella demostrarlos. La carga de la prueba mantiene su concepción clásica, pero en determinados casos hay un desplazamiento a una especie de solidaridad dentro de la concepción liberal para que el otro, que tiene la facilidad por motivos que no es necesario ni siquiera enunciar, ya que en cada caso y de conformidad con las reglas de la experiencia se llegará a concluir sobre a quién le quedaba más fácil probar un determinado hecho. $^{23}$

21. Id. Págs. 74 y ss.

22. Véase Luis Guillermo Acero Gallego. Modificación al régimen de la carga de la prueba en el Código General del Proceso. Horacio Cruz Tejada, Coord. El proceso CIVIL a PARTIR Del Código General Del Proceso. Universidad de los Andes, Facultad de Derecho. (2014). Págs. 217 y ss.

23. Véase Proyecto de ley del Código General del Proceso. Por medio del cual se expide el Código General del Proceso y se dictan otras disposiciones. Proyecto de Ley N. ${ }^{\circ} 159$ de 2011. Senado-196 de 2011 Cámara. Coord. P. senador Hernán Andrade.

\section{A. Fundamentos constitucional y legislativo}

En Colombia, la teoría de la carga dinámica de la prueba aparece consagrada expresamente a partir del Código General del Proceso, en su artículo 167, como ya se indicó. Sin embargo, su aplicación anterior a la vigencia de este estatuto, a casos específicos relacionados con la actividad médica, encuentra su sustento jurídico en algunas disposiciones contenidas en la Constitución Política, el Código de Procedimiento Civil y el Código Civil.

Los principios de flexibilización jurídica de la carga dinámica de la prueba están consagrados en los artículos 13 (igualdad procesal); solidaridad social (artículo 1); el derecho al acceso efectivo a la justicia (artículo 229); prevalencia del derecho sustancial (artículo 228); el principio del derecho a la defensa (artículo 29); en armonía con otros principios, como el de la buena fe (artículo 83); el de colaboración con la administración de justicia (artículo 95.7); y el de la equidad que debe imperar en toda actuación judicial (artículo 230). Con esto se garantiza el derecho a la obtención de la prueba en el momento en que una de las partes no tenga acceso a ella, por lo cual no resulta de buen recibo que aquella parte con facilidad para allegar pruebas se abstenga de hacerlo, ya que en este evento se perturbaría la investigación en el sentido de llegar a la verdad real y, por ende, el deber que le corresponde a los ciudadanos de colaborar con la administración de justicia, y correlativamente, de no entorpecer su normal desarrollo. ${ }^{24}$

El artículo 1604 del Código Civil de este estatuto, referido a la responsabilidad del deudor, al establecer en su inciso tercero la forma como se distribuye la carga de la prueba en la responsabilidad civil contractual, señala que la "prueba de la diligencia y cuidado incumbe al que ha debido emplearla; la prueba del caso fortuito al que lo alega". Esta norma contiene la regla de juicio en relación con la distribución de la carga de la prueba en los procesos de responsabilidad civil contractual, y que ha de aplicarse de manera general en el proceso civil:

Sin embargo, a pesar de su claridad, que emana diáfana de la norma y que no deja lugar a dudas de que en estos contenciosos es el deudor (para estos casos, el médico) el que debe demostrar la diligencia y cuidado. $^{25}$

24. Véase Luis Guillermo Acero Gallego, supra, nota 20. Págs. 44 y ss. 25. Id. Pág. 77 


\section{B. Fundamento en el Código de Procedimiento Civil y en el Código General del Proceso}

Así, los artículos 4 (interpretación de las normas procesales) y 5 (vacíos y deficiencias) del Código de Procedimiento Civil (artículos 11 y 12, respectivamente, del Código General del Proceso), le dan prevalencia al derecho sustancial sobre el formal y han sido objeto de pronunciamiento por parte de la Corte Constitucional, con la integración de algunos de los principios de este carácter:

Cuando el artículo 228 de la Constitución establece que en las actuaciones de la Administración de Justicia "prevalecerá el derecho sustancial", está reconociendo que el fin de la actividad jurisdiccional, y del proceso, es la realización de los derechos consagrados en abstracto por el derecho objetivo y, por consiguiente, la solución de los conflictos de intereses. Es evidente que en relación con la realización de los derechos y la solución de los conflictos, el derecho procesal, y específicamente el proceso, es un medio (...) El artículo 4 del Código de Procedimiento Civil, por su parte, expresa la misma idea al afirmar que al interpretar la ley procesal, el juez deberá tener en cuenta que el objeto, es decir, el fin de los procedimientos es la efectividad de los derechos reconocidos por la ley sustancial. También aquí la relación de medio a fin es ostensible. ${ }^{26}$

Con la consagración de la carga dinámica de la prueba en el Código General del Proceso, la carga estática vendrá a constituirse en regla general, en abstracto, mientras que la aplicación de la carga dinámica será objeto de análisis del juez para su aplicación, previo estudio de las particularidades del respectivo caso, en especial cuando se trata de pretensiones originadas en la actividad médica. En el proceso verbal del nuevo estatuto procesal, la oportunidad para distribuir la carga de la prueba viene a ser amplia y de ninguna manera dará lugar a su rechazo, pretextando imposición sorpresiva para el aporte de las evidencias o el esclarecimiento de los hechos controvertidos.

No obstante, la actuación del juez no tiene el carácter de imperativo ("podrá de oficio o a petición de parte, distribuir la carga"), ${ }^{27}$ y tal como lo señala la norma comentada, se presentarán casos en que, en

26. Véase Corte Constitucional de Colombia. SentenCia C-020 DE 1995. (M.P. María Victoria Calle; Enero 21 de 2015).

27 Véase Ley 1564 de 2012. Art. 167, Inc. 2. Por medio de la cual se expide el Código General del Proceso y se dictan otras disposiciones. Julio 12 de 2012. Do N. ${ }^{\circ} 48489$. principio, no exista claridad acerca de la parte con acceso fácil a una prueba, o bien que ninguna de las partes la tenga. En este evento, no podría omitirse la aplicación de la regla general (carga estática de la prueba), pero solo después de analizar esta especial situación, sin perder de vista la facilidad probatoria del médico (o entidad médica) para acompañar al proceso los documentos que tenga en su poder (historia clínica, etc.), con el fin de demostrar su diligencia y cuidado en la realización del acto médico. La anterior actuación del juez estará en conformidad con la función pública del proceso.

Entre los aspectos importantes que tienen que ver, la carga de la prueba y la distribución real de ella no acorde con la regla general, para configurar la teoría de la carga dinámica de la prueba, suelen utilizarse diferentes mecanismos a fin de trasladar la carga de la prueba de la parte que, en teoría, debe probar un hecho, a la otra parte. Uno de ellos empleado para llegar a estos cambios viene a concretarse en el posible acuerdo entre las futuras partes, antes de la iniciación del proceso. Esta práctica es admisible en Inglaterra, Alemania, Francia y España (con aplicación en Colombia). Dicha clase de acuerdos suelen incluirse en los contratos de prestación de servicios médicos, aun cuando no se encuentren regulados expresamente en la ley. ${ }^{28}$

De igual manera, "el artículo 2.698 del Código Civil Italiano admite tales acuerdos siempre que versen sobre situaciones jurídicas disponibles para las partes en privado y que ninguna de ellas afronte dificultades excesivas al reclamar su propio derecho como consecuencia del acuerdo." ${ }^{29}$ La consagración de la carga dinámica de la prueba en el CGP humaniza los procesos de esta naturaleza, a la vez que se aproximarán a la obtención de la verdad real en aras de procurar decisiones justas y evitar fallos absolutorios incongruentes, cuando la parte actora, ante la dificultad de la prueba, debía soportar el onus probandi.

\section{B. Fundamento doctrinal}

Finalmente, el profesor Jaramillo, ${ }^{30}$ en alusión al inciso 1 del artículo 177 del anterior estatuto procesal, expresa:

\footnotetext{
28. Estos acuerdos tendrían validez tanto durante el desarrollo de la conciliación extraprocesal, como en el de la audiencia de iniciación y conciliación, una de las actuaciones orales dentro de los procesos verbales.

29. Véase Michele Taruffo. La prueba. Marcial Pons. (2008). Pág. 151.

30. Véase Carlos Ignacio Jaramillo J. LA CULPA Y LA CARGA DE LA PRUEBA EN EL CAMPO DE LA RESPONSABILIDAD MÉDICA. Grupo Editorial Ibáñez. (2010). Pág. 270.
} 
Por consiguiente, el primer inciso de la disposición contenida en el artículo 177 del c. de P.C. se ocupa de delinear la regla general imperante en materia del onus probandi, al poner de presente que, 'Incumbe a las partes probar el supuesto de hecho de las normas que consagren el efecto jurídico que ellas persiguen', regla que, en el caso en particular, puede ser exceptuada. No en vano toda regla, bien se sabe, admite excepciones; de lo contrario, serían preceptos absolutos e inmodificables, lo que no está en consonancia con la realidad probatoria que, de antaño, como se demostró y se confirmará (capítulo viII), ha admitido distribuir la carga de la prueba en función de la dificultad probática.

\section{LÍNEA JURISPRUDENCIAL}

Para lograr el objetivo general de la investigación, se proyectan los siguientes objetivos específicos: clasificar las sentencias de la Corte Suprema de Justicia; construir una línea jurisprudencial sobre la evolución de la carga de la prueba en la jurisdicción civil de conformidad con la metodología de la Escuela Rodrigo Lara Bonilla; y determinar las tendencias jurisprudenciales de la Corte Suprema de Justicia en procesos de responsabilidad médica.

Para la realización de esta investigación de tipo descriptivo, con técnicas de revisión documental, se emplea el método deductivo. El trabajo comprende las siguientes etapas desarrolladas en veinticuatro meses (2013-2014): recopilación de sentencias de la Corte Suprema de Justicia en el período 1990-2014; lectura de los documentos; sistematización; interpretación de resultados; y conclusiones.

Como resultado de la investigación, se exponen las principales sentencias de la Corte Suprema de Justicia, Sala Civil y Agraria, que desarrollan la línea jurisprudencial de la carga de la prueba. Para su análisis se seleccionaron la fundadora de línea, la hito y la arquimédica. Igualmente, se relacionan las sentencias confirmadoras de línea que responden al problema jurídico: a fin de establecer la responsabilidad civil médica, incumbe probar los supuestos de hecho conforme (polo A) la carga estática de la prueba y (polo $\mathrm{B}$ ) la carga dinámica de la prueba.

\section{A. Sentencia fundadora de línea e hito}

En este fallo, de fecha 5 de marzo de 1940 de la Corte Suprema de Justicia, Sala Civil, se establece que la obligación del médico es de medio y no de resultado; por lo tanto, el facultativo está obligado a desplegar a favor de su cliente conocimientos científicos tales como pericia, cuidados y prudencia, sin que pueda ser responsable del resultado adverso de la enfermedad padecida por el paciente o de su no curación.

En esta jurisprudencia, se determinó que:

Si bien el pacto de prestación del servicio médico puede generar diversas obligaciones a cargo del profesional que lo asume, y que atendiendo a la naturaleza de éstas dependerá, igualmente, su responsabilidad, no es menos cierto que, tratándose de la ejecución del acto médico propiamente dicho, deberá indemnizar, en línea de principio y dejando a salvo algunas excepciones, los perjuicios que ocasione mediando culpa o dolo, cuya carga probatoria asume el demandante, sin que sea admisible un principio general encaminado a establecer de manera absoluta una presunción de culpa de los facultativos. ${ }^{31}$

\section{B. Sentencias confirmadoras de línea}

En el análisis desarrollado, se encontró que la carga estática de la prueba se consolida con los siguientes fallos. La Sentencia del 12 de septiembre de 1985 afirma que la obligación del médico consiste en poner en actividad todos los medios que tenga a su alcance para la curación del enfermo. Posteriormente, en Sentencia del 26 de noviembre de 1986, se ratificó la doctrina, invocando la Sentencia del 5 de marzo de 1940, pero deja a salvo, en el campo de la responsabilidad contractual, el caso de que en el contrato se hubiere llegado a asegurar determinado resultado, ya que si no lo obtiene, en expresión de la Corte será culpable y con la obligación de indemnizar a la víctima, a no ser que se llegue a la demostración de alguna causal de exoneración, como fuerza mayor, caso fortuito o culpa de la perjudicada, agrega la providencia.

\section{Sentencia hito}

No obstante los anteriores pronunciamientos, la Corte produjo cambio de línea, en virtud de la Sentencia del 30 de enero de 2001, al señalar lo siguiente:

En conclusión y para ser coherentes en el estudio del tema, se pudiera afirmar que en este tipo de responsabilidad como en cualquiera otra, deben concurrir todos los elementos o presupuestos materiales para

31. Véase Corte Suprema de Justicia. Sala Civily Agraria. Sentencia DEL 5 DE MARZO DE 1940. (M.P. Liborio Escallón). 
el éxito de la pretensión, empezando por supuesto con la prueba del contrato, que es carga del paciente, puesto que es esta relación jurídica la que lo hace acreedor de la prestación del servicio médico, de la atención y el cuidado. Igualmente, corresponde al paciente probar el daño padecido (lesión física o psíquica), y consecuentemente el perjuicio patrimonial o moral cuyo resarcimiento pretende. Ahora bien, probado este último elemento, sin duda alguna, como antes se explicó, que lo nuclear del problema está en la relación de causalidad adecuada entre el comportamiento activo o pasivo del deudor y el daño padecido por el acreedor, pues es aquí donde entran en juego los deberes jurídicos de atención y cuidado que en el caso concreto hubo de asumir el médico y el fenómeno de la imputabilidad, es decir, la atribución subjetiva, a título de dolo o culpa. Pero es precisamente en este sector del comportamiento en relación con las prestaciones debidas, donde no es posible sentar reglas probatorias absolutas con independencia del caso concreto, pues los habrá donde el onus probandi permanezca inmodificable, o donde sea dable hacer actuar presunciones judiciales, como aquellas que en ocasiones referenciadas ha tenido en cuenta la Corte, pero también aquellas donde cobre vigencia ese carácter dinámico de la carga de la prueba, para exigir de cada una de las partes dentro de un marco de lealtad y colaboración, y dadas las circunstancias de hecho, la prueba de los supuestos configurantes del tema de decisión. Todo, se reitera, teniendo en cuenta las características particulares del caso: autor, profesionalidad, estado de la técnica, complejidad de la intervención, medios disponibles, estado del paciente y otras circunstancias exógenas, como el tiempo y el lugar del ejercicio, pues no de otra manera, con justicia y equidad, se pudiera determinar la corrección del acto médico (lex artix). ${ }^{32}$

La anterior posición de la Corte - que acoge la teoría de la carga dinámica de la prueba- ha sido confirmada por las sentencias del 30 de noviembre de 2011 y del 15 de septiembre de 2014.

\section{Sentencia arquimédica}

Esta clase de sentencia constituye el punto de apoyo con el que se trata de desenredar las relaciones surgidas entre las varias sentencias objeto de análisis jurisprudencial. Con ella se logra la identificación de la

32. Véase Corte Suprema de Justicia. Sala Civil y Agraria. Sentencia DEL 30 DE NOVIEMBRE DE 2011. (M.P. Arturo Solarte Rodríguez). sentencia hito, caracterizada por ser fundamental en la investigación y sistematización de la línea.

Los hechos relevantes de la Sentencia arquimédica del 14 de noviembre de 2014 están en armonía con el problema jurídico, objeto de este análisis, como lo es la aplicación de la carga dinámica de la prueba en los procesos relacionados con la responsabilidad médica. En este fallo, la parte actora formula reclamaciones originadas en una indebida prestación de los servicios médicos, y allí se consigna que el esfuerzo de la demostración de los hechos corresponde a quien los invoca. Para la Sala, en alusión a la Sentencia del 5 de marzo de 1940, por regla general, las obligaciones que surgen de vinculaciones de este tipo son de medio, por lo cual se debe establecer "no solo la certidumbre de la culpa del médico, sino también la gravedad". ${ }^{33}$

\section{CONCLUSIONES}

Esta investigación establece la línea jurisprudencial con los criterios de la Jurisdicción Civil, que evidencia la tendencia sobre la carga de la prueba en procesos de responsabilidad médica desde 1940 hasta el año 2014. Los principales criterios que se encontraron son:

- Para la configuración de la culpa médica, se considera que la responsabilidad del médico no es ilimitada ni motivada por cualquier causa, por cuanto se exige no solo la certidumbre de la culpa, sino también su gravedad.

- El onus probandi no es un postulado absoluto, puesto que si en la práctica el profesional se compromete con un resultado específico, como ocurre con algunas intervenciones estéticas, o se dan circunstancias que dificultan ostensiblemente la actividad probatoria del gestor, puede el fallador morigerar la carga de la prueba. En estos eventos, es razonable que se apliquen los conocimientos adquiridos en el ejercicio de la función judicial, así como las reglas de equidad, y que se extraigan del material sobrante deducciones en relación con el comportamiento de los litigantes o un conjunto de indicios sobre la conducta lesiva.

- Es la relación jurídica particularmente creada la que ofrecerá los elementos que permitan identificar cuál fue realmente la prestación prometida.

- En la responsabilidad deben concurrir todos los elementos o presupuestos materiales para el éxito 
de la pretensión, empezando, por supuesto, con la prueba del contrato, que es carga del paciente.

- Corresponde al paciente probar el daño padecido (lesión física o psíquica), y consecuentemente, el perjuicio patrimonial o moral cuyo resarcimiento pretende.

- En la relación de causalidad entre el comportamiento del médico y el daño sufrido por el paciente, se configura un elemento indispensable: la causa eficiente de los perjuicios que se ocasionen al paciente.

- En el campo de la responsabilidad civil, el acto médico puede generar para el profesional que lo ejercita obligaciones de carácter indemnizatorio por perjuicios causados al paciente, como resultado de incurrir en yerros de diagnóstico y de tratamiento, bien sea porque actúe con negligencia o impericia en el establecimiento de las causas de la enfermedad, o en la naturaleza misma de esta; o bien porque a consecuencia de aquello ordene medicamentos o procedimientos de diversa índole inadecuados que agravan su estado de enfermedad; o bien porque ese estado de agravación se presenta simplemente por exponer al paciente a un riesgo injustificado o que no corresponda a sus condiciones clínico-patológicas.

- Una rigurosa aplicación de la disposición contenida en el artículo 177 del Código de Procedimiento Civil puede aparejar en este ámbito el fracaso de la finalidad reparadora del régimen de la responsabilidad civil, particularmente dadas las dificultades probatorias en las que se puede encontrar la víctima. No es insensible la Corte ante esa situación, motivo por el cual asienta que, teniendo en consideración las particularidades de cada caso en concreto, lo que repele cualquier intento de generalización o de alteración de los principios y mandatos legales, y en la medida en que sea posible, puede el juez acudir a diversos instrumentos que atenúan o "dulcifican" (como lo denominan la doctrina y la jurisprudencia españolas), el rigor del reseñado precepto.

- Es posible que el juez, con sujeción a las normas jurídicas y de la mano de las reglas de la experiencia, el sentido común, la ciencia o la lógica, deduzca ciertas presunciones relativas a la culpa galénica; o bien que lo haga a partir de indicios derivados de la conducta de las partes, o que acuda a razonamientos lógicos como el principio res ipsa loquitur (como cuando se olvida una gasa o material quirúrgico en la zona intervenida, o se amputa el miembro equivocado, etc.); o que teniendo en consideración la manifiesta anormalidad de las consecuencias del acto médico, deduzca una "culpa virtual" o un "resultado desproporcionado", todo lo anterior, se reitera, sin que sea admisible la aplicación de criterios generales que sistemática e invariablemente quebranten las reglas de distribución de la carga de la prueba previstas en el ordenamiento.

- El carácter dinámico de la carga de la prueba exige de cada una de las partes, dentro de un marco de lealtad y colaboración, la prueba de los supuestos configurantes del tema de decisión.

En términos generales, el planteamiento original de la Corte se ha mantenido hasta el presente, destacándose en los pronunciamientos de la corporación la trascendencia de la clasificación de que se trata, particularmente respecto a la determinación del contenido de las obligaciones para la definición de su cumplimiento o incumplimiento, así como en lo atinente a su influencia en las cargas probatorias de las partes. Estima la Corte que la clasificación de las obligaciones en "de medio" y "de resultado" sigue siendo una herramienta útil para el juzgador a fin de determinar el comportamiento que deben asumir los contratantes, y contribuye a encontrar criterios aplicables a la definición de las cargas probatorias en la responsabilidad civil contractual. Sin embargo, como también lo ha señalado la Sala luego de censurar indebidas generalizaciones, lo fundamental está en identificar el contenido y alcance del contrato celebrado en el caso concreto, así como los particulares deberes de prestación que de él hayan surgido.

Por último, la Sentencia del 14 de noviembre de 2014, establece que en la Ley 1564 de 2012, la cual adoptó el Código General del Proceso, "incumbe a las partes probar el supuesto de hecho de las normas que consagran el efecto jurídico que ellas persiguen", ${ }^{34} \mathrm{e}$ introduce explícitamente el concepto de carga dinámica de la prueba en los siguientes términos:

No obstante, según las particularidades del caso, el juez podrá, de oficio o a petición de parte, distribuir la carga al decretar las pruebas durante su práctica o en cualquier momento del proceso antes de fallar, exigiendo probar determinado hecho a la parte que se encuentre en una situación más favorable para aportar las evidencias o esclarecer los hechos controvertidos. La parte se considerará en mejor posición para probar en virtud de su cercanía con el material probatorio, por tener en su poder el objeto de

34. Véase Corte Suprema de Justicia, supra, nota 33. 
prueba, por circunstancias técnicas especiales, por haber intervenido directamente en los hechos que dieron lugar al litigio, o por estado de indefensión o de incapacidad en el cual se encuentre la contraparte, entre otras circunstancias similares (...) Cuando el juez adopte esta decisión, que será susceptible de recurso, otorgará a la parte correspondiente el término necesario para aportar o solicitar la respectiva prueba, la cual se someterá a las reglas de contradicción previstas en este código.

\section{REFERENCIAS}

Antonio Michelli. La Carga de la PrUeba. Mundo Editores. (1982).

Carlos Ignacio Jaramillo. LA CULPA Y LA CARGA DE LA PRUEBA EN EL CAMPO DE LA RESPONSABILIDAD MÉDICA. Grupo Editorial Ibáñez. (2010).

Consejo de Estado. Sección Tercera. Sala de lo Contencioso Administrativo. SentenCIA DEL 3 O DE JULIO DE 1992. (M.P. Daniel Suárez Hernández; Julio 30 de 1992).

Corte Constitucional de Colombia. Sentencia C-020 DE 1995. (M.P. María Victoria Calle; Enero 21 de 2015).

Corte Suprema de Justicia. Sala Civil y Agraria. Sentencia DEL 5 DE MARZO DE 1940. (M.P. Liborio Escallón).

Corte Suprema de Justicia. Sala de Casación Civil. Auto DE FECHA 17 DE SEPTIEMBRE DE 1985.

Corte Suprema de Justicia. Sala Civil y Agraria. ExPEDIENTE N. ${ }^{\circ}$ 5507. (M.P. José Fernando Ramírez; Enero 30 de 2001).

Corte Suprema de Justicia. Sala Civil y Agraria. Sentencia DEL 13 DE SEPTIEMBRE DE 2002. (M.P. Nicolás Bechara Simancas).

Corte Suprema de Justicia. Sala de Casación Civil y Agraria. EXPEDIENTE 2002-00373-01. (M.P. William Namén; Enero 25 de 2008).

Corte Suprema de Justicia. Sala Civil y Agraria. Sentencia DEL 22 DE JULIO DE 2010. (M.P. Pedro Octavio Cadena Munar).

Corte Suprema de Justicia de Colombia. Sala de Casación Civil. ExPEDIENTE 2005-00025-01. (M.P. Arturo Solarte; Noviembre 5 de 2013).
Corte Suprema de Justicia. Sala Civil y Agraria. Sentencia DEL 15 DE SEPTIEMBRE DE 2014. (M.P. Margarita Cabello Blanco).

Corte Suprema de Justicia. Sala de Casación Civil y Agraria. RADICACIÓN: 11001-31-03-029-2008-00469-01. (M.P. Fernando Giraldo Gutiérrez; Noviembre 14 de 2014).

Enrico Tullio Liebman. Manual de Derecho Procesal Civil. Ediciones Jurídicas Europa América. (1980).

Francisco Carnelutti. LA PRUeba civil. Niceto Alcalá-Zamora y Castillo, Trad. Ediciones Depalma. (1979).

Francisco Ramos Méndez. Derecho Procesal Civil. Librería Bosch Barcelona. (1986)

Hernando Devis Echandía. Compendio de Derecho Procesal. Pruebas judiciales. Editorial Diké. (1999).

Jairo Parra Quijano. Manual de Derecho Probatorio. Librería Ediciones del Profesional. (2004).

Jeremías Bentham. Tratado de las pruebas judiciales. Ediciones Nueva Jurídica. (2000).

Jorge Peyrano y Julio O. Chiappini. Lineamientos generales de las cargas probatorias "dinámicas". CARGAS PROBATORIAS DINÁmICAS. Rubinzal-Culzoni Editores. (2004).

Julio Trujillo Cabrera. LA CARGa DE LA PRUEBa. Leyer Editorial. (2006).

Leo Rosemberg. LA CARGa DE LA PRUEBA. Editorial B de F. (2002)

Ley 1564 de 2012. Por medio de la cual se expide el Código General del Proceso y se dictan otras disposiciones. Julio 12 de 2012. Do N. ${ }^{\circ} 48489$.

Luis Guillermo Acero Gallego. Modificación al régimen de la carga de la prueba en el Código General del Proceso. EL proceso Civil a partir del Código General deL Proceso. Coord. Horacio Cruz Tejada. Universidad de los Andes, Facultad de Derecho. (2014).

Luis Guillermo Serrano Escobar. El RÉGIMEN PROBATORIO EN LA RESPONSABILIDAD MÉDICA. Ediciones Doctrina y Ley. (2012).

Michele Taruffo. La prueba. Marcial Pons. (2008).

Ricardo Luis Lorenzetti. Responsabilidad CIVIL DE LOS MÉDICOS. Tomo II. Rubinzal-Culzoni Editores. (1997). 